\title{
Evaluation of Early High Speed Development of Bottom Water Heavy Oil Reservoir
}

\author{
Xiujuan Zhao*, Songru Mou, Jie Tan, Bowei Liu, Enhui Sun \\ Bohai Oilfield Research Institute of CNOOC Ltd.-Tianjin Branch, Tianjin, China \\ Email: ^16890452@qq.com
}

How to cite this paper: Zhao, X. J., Mou, S. R., Tan, J., Liu, B. W., \& Sun, E. H. (2020). Evaluation of Early High Speed Development of Bottom Water Heavy Oil Reservoir. Journal of Geoscience and Environment Protection, 8, 201-208.

https://doi.org/10.4236/gep.2020.811013

Received: October 10, 2020

Accepted: November 24, 2020

Published: November 27, 2020

Copyright $\odot 2020$ by author(s) and Scientific Research Publishing Inc. This work is licensed under the Creative Commons Attribution International License (CC BY 4.0).

http://creativecommons.org/licenses/by/4.0/

\begin{abstract}
The bottom water heavy oil reservoir has high natural energy, and the bottom water body multiple of the reservoir is 300 times or even higher. The natural energy of the reservoir can keep the superior condition that the formation energy does not decrease under the condition of large liquid volume and high recovery rate. In view of this reservoir condition, we take $\mathrm{C}$ oilfield as an example to carry out the oilfield development effect under the condition of large liquid volume and high-speed production, and analyze the influence of high-speed production and medium low-speed production on recovery rate of similar heavy oil bottom water-reservoir. The results show that the rising trend of water cut in oilfield is the same whether high-speed development with large liquid volume or conventional low-speed development is adopted. Under the condition of high liquid production, the sweep efficiency of water flooding is high in the same period of time, which has certain advantages of enhanced oil recovery. The development mode of early large liquid production is explored, which provides certain guidance for the efficient development of heavy oil reservoir with bottom water.
\end{abstract}

\section{Keywords}

Bottom Water, Heavy Oil, High Speed Development

\section{Introduction}

C oilfield is dominated by thin-layer heavy oil reservoir with strong bottom water. The average effective thickness of oil layer is $11 \mathrm{~m}$. The vertical distribution range of formation crude oil viscosity is $30 \mathrm{MPa} \cdot \mathrm{s}$ - $425 \mathrm{MPa} \cdot \mathrm{s}$ from deep to shallow. The reservoir has good physical properties with an average permeability of $3000 \mathrm{md}$ and sufficient energy of bottom water. After more than ten years of production, the formation pressure has basically remained unchanged. In the 
process of oilfield development, the water cut of oil wells rises rapidly and the degree of water drive is low. At present, the comprehensive water cut is $96.1 \%$ and the recovery degree is $10.3 \%$. The core of this kind of reservoir development is how to expand sweep, increase reserves and effectively produce. The common technology of similar reservoir development is to slow down the oilfield production by multiple sidetracking after the high water cut stage. This paper evaluates the oil recovery rate through the initial high-speed and high-volume development, so as to reduce the frequent sidetracking and reduce the development cost of the oilfield (Liu et al., 2002) (Li \& Meng, 1994) (Lu, 2010) (Hou et al., 2006) (Cao et al., 2014) (Nie et al., 2012).

Taking Minghuazhen Formation sand body of $\mathrm{C}$ oilfield as the key research object, this paper studies the influence of liquid production rate on oil recovery. It mainly includes the following aspects: 1) analyzing the historical production dynamic characteristics of sand body in upper Ming section of $\mathrm{C}$ oilfield; 2) analyzing the influence of fluid production rate on oil recovery by using mathematical model analysis; 3) comparing the production effect of high and low speed in actual oilfield.

\section{Effect Evaluation of Early Large Liquid Development}

\subsection{In Large Liquid Production, the Rising Law of Water Content Is Basically Consistent with That of Conventional Liquid Production}

For edge and bottom water reservoirs, the traditional idea is that the water cut rise should be controlled by small pressure difference at the initial stage of production, to prolong the production time in the low water cut stage as much as possible. C oilfield has two typical reservoir characteristics: first, the viscosity of underground crude oil is high, and the viscosity of underground crude oil in Ming Formation reservoir is 142 - $425 \mathrm{MPa} \cdot s$; Secondly, the structural amplitude of sand body is low $(10 \mathrm{~m}-30 \mathrm{~m})$, the height of oil column is small, the average is $9 \mathrm{~m}$, the development of internal interlayer is poor, and the energy of edge and bottom water is sufficient. Based on the above reservoir characteristics, during the horizontal development of $\mathrm{C}$ oilfield, the water cut of oil wells rises rapidly after putting into production, and the progress of bottom water cone cannot be restrained. Theoretical calculation and production performance show that the critical production of horizontal wells in Ming Formation bottom water heavy oil reservoir of $\mathrm{C}$ oilfield is small, which cannot meet the actual production demand, and the actual production of horizontal wells is basically no water free oil production Period. According to the actual production data of horizontal wells in the oilfield, the water breakthrough time and the relationship between initial water cut and production pressure difference of 26 typical horizontal wells in $\mathrm{C}$ oilfield are compared (Figure 1). By contrastive analysis, it's found that there is no obvious corresponding relationship among breakthrough time of water cut, initial water cut, and production pressure difference in horizontal wells of $\mathrm{C}$ 


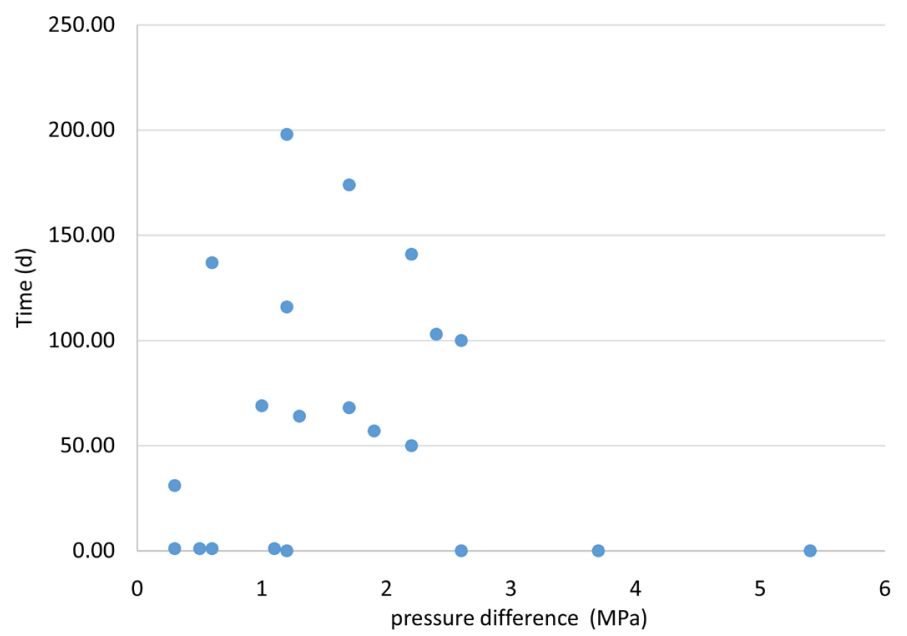

Figure 1. The relationship between the water breakthrough time and production pressure difference.

oilfield (Xiong et al., 2014) (Chang et al., 2020) (Xin, 2011) (Liu, 2012) (Fan \& Lin, 1994) (Xiao et al., 2009).

\subsection{The Energy of Bottom Water Is Sufficient and There Is a Material Basis for Large-Scale Exploitation}

The sand body of Ming Formation in C oilfield has strong bottom water energy. After the oilfield is put into operation, the formation pressure is basically stable near the original formation pressure. The dimensionless liquid production index calculated by the relative permeability curve of different sand bodies in this interval shows that the dimensionless liquid production index is 5 - 20 times of that in the initial stage when the water content is $50 \%-90 \%$. The initial production capacity is $100-230 \mathrm{~m}^{3} / \mathrm{d}$ that has the material basis for early large liquid production (Figure 2).

\section{Effect of Recovery Rate on Recovery of Heavy Oil Reservoir with Low Oil Column and Bottom Water}

\subsection{Mechanism Study}

Based on the physical property characteristics, fluid properties and relative permeability curves of upper Ming formation in $\mathrm{C}$ oilfield, the mechanism model is established for research. In the model, the plane mesh number is $87 \times 89$, the step size is $10 \mathrm{~m}$, the longitudinal mesh number is 18 , the step size is $1 \mathrm{~m}$, and the total mesh number is 139374 (Figure 3 and Figure 4).

The actual model of a sand body in $\mathrm{C}$ oilfield is used for research. The results show that the horizontal grid number is $98 \times 57$, the step length is $50 \mathrm{~m}$, the vertical grid number is 20 , the step size is $0.75-1 \mathrm{~m}$, the water body size is 50 times, the permeability is $(2000-5000) \times 10^{-3} \mu \mathrm{m}^{2}$. The relative permeability curve and formation crude oil viscosity are the same as the mechanism model.

It can be seen that in the case of fixed liquid production, the cumulative oil 


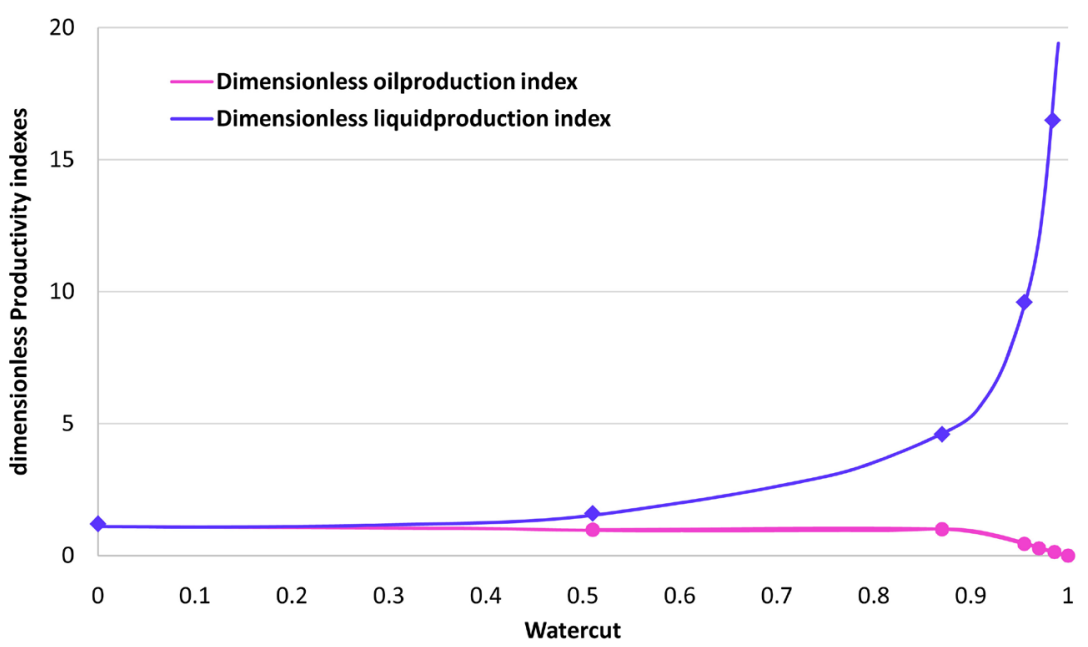

Figure 2. Dimensionless oil production and liquid production index of Minghuazhen Formation sand body in C Oilfield.

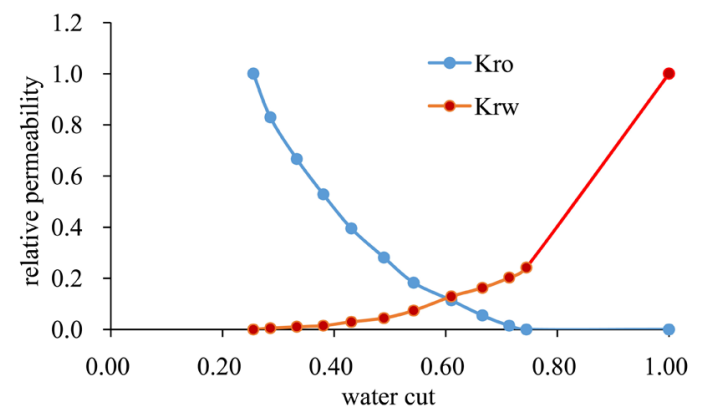

Figure 3. Phase permeability curve.

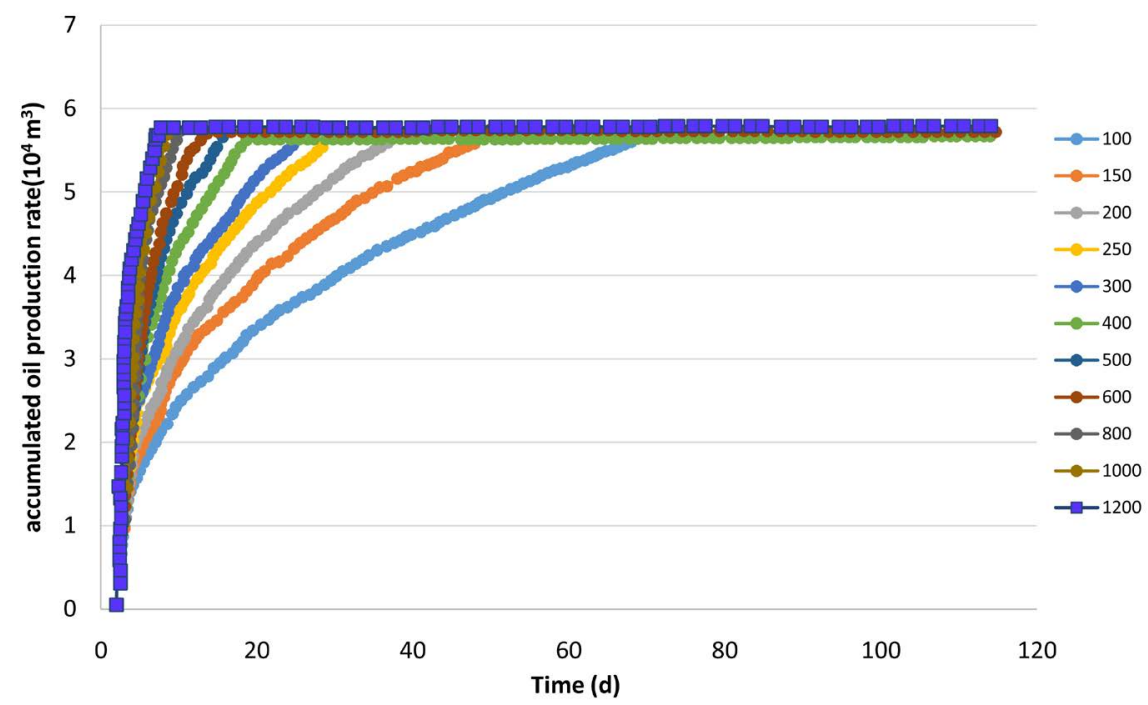

Figure 4. The change of cumulative oil production when water cut reaches $98 \%$.

production of different liquid production rates of the mechanism model and the actual model are basically unchanged. The total cumulative oil production of five wells in the mechanism model is $5.7 \times 10^{4} \mathrm{~m}^{3}$, and the recovery factor is $3.5 \%$; 
the total cumulative oil production of 10 wells in the actual model is $19.5 \times 10^{4}$ $\mathrm{m}^{3}$, and the recovery factor is $3.1 \%$. It can be concluded that for heavy oil reservoir with low oil column and bottom water in upper Ming member of C oilfield, the recovery rate has little effect on its recovery.

In view of this conclusion, it is studied from the mechanism that the recovery factor is composed of sweep efficiency and movable oil recovery degree. Starting from the influence of liquid production rate on sweep efficiency and movable oil recovery degree, the influence of liquid production rate on oil recovery is analyzed.

\section{1) Influence of liquid production rate on sweep efficiency}

According to the statistics, the sweep efficiency changes when the water cut reaches $98 \%$ is shown in Figure 5. The statistical method is as follows: the original oil saturation of the model is 0.75 . If the oil saturation of the model grid changes by 0.02 , it is considered that the grid is affected by water waves, and the number of swept grids is counted. Finally, the volume sweep efficiency is obtained by dividing the number of grids swept under different daily liquid production and the total number of original oil-bearing grids.

It can be seen from Figure 5 that the sweep efficiency increases with the increase of liquid production rate, which is due to the increase of liquid production rate and the increase of production pressure difference. Therefore, the crude oil in some reservoirs with relatively poor physical properties is started to participate in the flow. When the liquid production rate is greater than a certain value (mechanism model $300 \mathrm{~m}^{3} / \mathrm{D}$, actual model $500 \mathrm{~m}^{3} / \mathrm{D}$ ), both of them basically tend to be fixed value. Due to the increase of liquid production rate, the rising speed of water is higher than the sweep speed of water drive, which results in the shortening of the time when the water cut reaches $98 \%$ and the well is shut in.

\section{2) Effect of Fluid Production Rate on Recovery Degree of Movable Oil}

The changes of movable oil recovery degree when water cut reaches $98 \%$ under different daily liquid production are shown in Figure 6. The statistical method is as follows: the original oil saturation of the model is known to be 0.75 , so the residual oil saturation SOR in swept volume after water flooding can be read out from the model to calculate the recovery degree of movable oil.

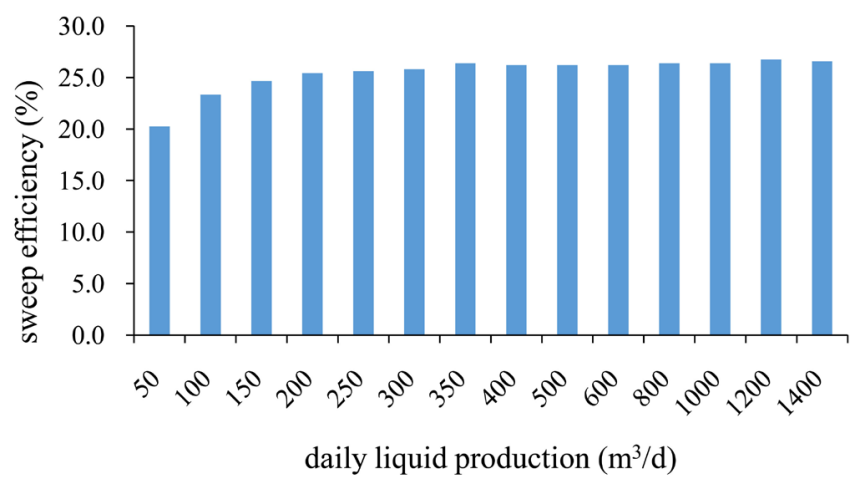

Figure 5. The sweep efficiency. 


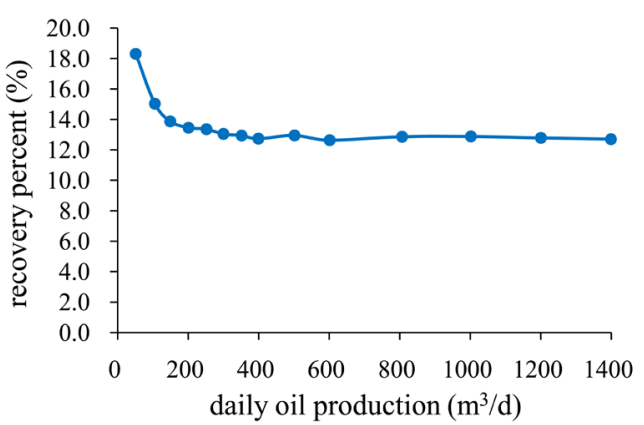

Figure 6. The recovery percent.

The recovery percent of movable oil decreases with the increase of liquid production rate. When the liquid production rate is greater than a certain value (mechanism model $300 \mathrm{~m}^{3} / \mathrm{D}$, actual model $500 \mathrm{~m}^{3} / \mathrm{D}$ ), both of them basically tend to fixed value. With the increase of liquid production rate, the sweep volume is increased. However, when the water cut reaches $98 \%$, the grid oil saturation does not reach the strong water flooding state, resulting in a high average residual oil saturation in the swept area, so the movable oil recovery degree decreases. When the liquid production rate is greater than a certain value, the sweep efficiency remains unchanged, leading to the same displacement efficiency.

It can be seen from the attached Figure 7 that the recovery factors of different recovery rates are basically the same, because the sweep efficiency and the recovery degree of movable oil are affected by the fluid production rate on the contrary. When the liquid production rate is greater than a certain value (mechanism model $300 \mathrm{~m}^{3} / \mathrm{D}$, actual model $500 \mathrm{~m}^{3} / \mathrm{D}$ ), they tend to be fixed values.

\subsection{Comparison of Actual Production Effect}

Both Ming oil formation in west area of D oilfield and upper Ming oil formation of $\mathrm{C}$ oilfield are bottom water heavy oil reservoirs. Their reservoir physical properties are similar, with average porosity of 0.3 and average permeability of $3000 \mathrm{md}$. Among them, crude oil viscosity of Ming oil formation in D oilfield is $260 \mathrm{mPa} \cdot \mathrm{s}$, and that of upper Ming sandstone formation in C oilfield is $350-425$ $\mathrm{mPa} \cdot \mathrm{s}$. seven horizontal wells put into operation after 2005 are selected from these two oil formations The average oil column height of sand body is $15 \mathrm{~m}$ and $13 \mathrm{~m}$ respectively. The low liquid production mode of $50-200 \mathrm{~m}^{3} / \mathrm{D}$ is adopted in D oilfield, and $400-1200 \mathrm{~m}^{3} / \mathrm{D}$ high liquid production mode is adopted in C oilfield. The low water cut period of the former lasted for 10 months, while that of the latter lasted only 3 months, indicating that low liquid production can prolong the production time of low water cut.

By comparing the cumulative oil production ratio at different water cut stages, it can be seen that most of the crude oil is recovered from the high water cut stage (FW $>90 \%$ ) regardless of low or high liquid production, and the proportions are $60 \%$ and $70 \%$ respectively.

Figure 8 shows the relationship curve between water cut and recovery degree 


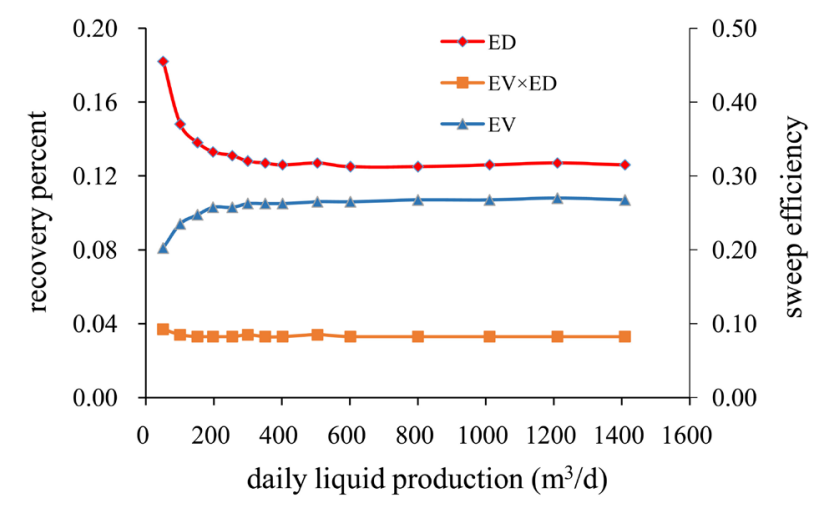

Figure 7. The recovery factors of different recovery rates.

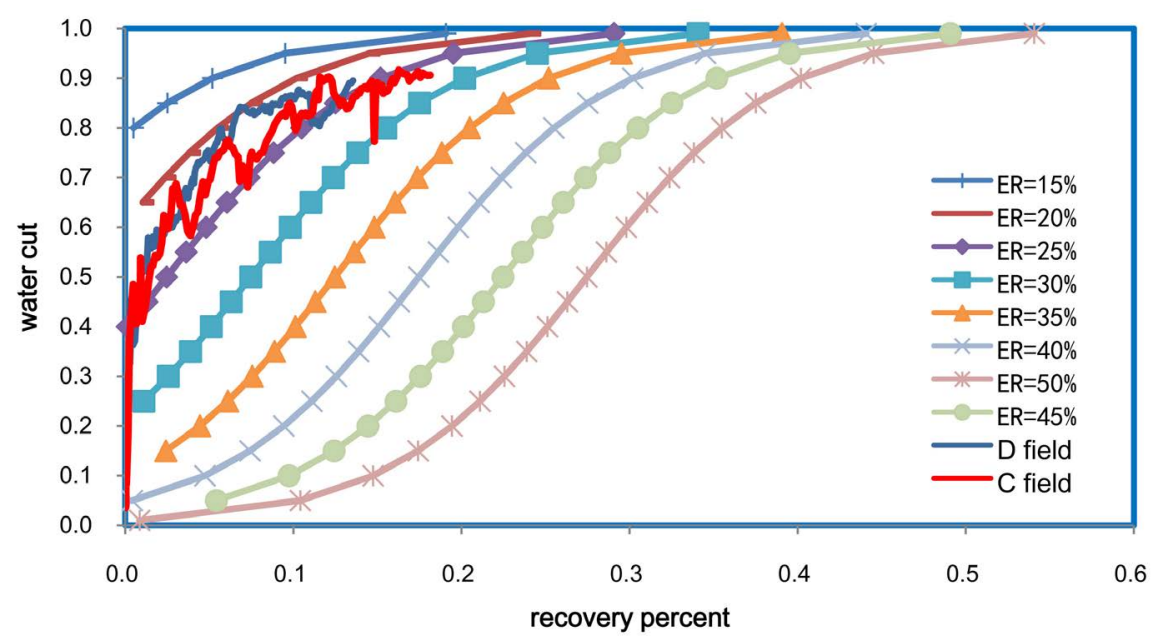

Figure 8. The relationship curve between water cut and recovery degree.

of oil formation under high and low liquid production development modes of $\mathrm{C}$ and D oilfields. It can be seen that in low liquid production of $\mathrm{D}$ oilfield, the recovery degree in low water cut period is only $1.6 \%$, while in Caofeidian high liquid production, bottom water breakthrough is fast, and there is basically no low water cut stage. However, no matter high liquid production or low liquid production, once the bottom water breakthrough occurs, the water cut will rise rapidly, and the later stage will increase the two curves tend to intersect, and the recovery degree of the two mining modes is basically the same. The final recovery factor of the two models is predicted by Tong's chart method.

\section{Conclusion}

Based on the production law of heavy oil bottom water-reservoir, this paper summarizes the development effects of different development strategies in the early stage of oilfield development. The research results show that the oil fields with sufficient natural energy have the reservoir conditions of early high-speed and large liquid production. At the same time, the recovery efficiency of reservoir development has little difference under different working systems of liquid production rate. Therefore, for heavy oil reservoirs with rigid bottom water, high 
speed development mode can be adopted to recover oilfield investment quickly and improve economic benefits of oilfield development.

\section{Conflicts of Interest}

The authors declare no conflicts of interest regarding the publication of this paper.

\section{References}

Cao, P., Chang, S. Y., Dai, C. R. et al. (2014). Research Progress of Horizontal Well Water Ridge in Bottom Water Reservoir. Journal of Chongqing University of Science and Technology: Natural Science Edition, 16, 63-66.

Chang, T., Chen, J. B., Liu, J. G. et al. (2020). A Rapid Evaluation Method for Development Potential of Bottom Water Reservoir. Daqing Petroleum Geology and Development, $39,65-71$.

Fan, Z. F., \& Lin, Z. F. (1994). Study on Critical Production Formula of Horizontal Wells in Bottom Water Drive Reservoir and Its Variation Rule. Petroleum Exploration and Development, 12, 65-70.

Hou, J., Cheng, L. S., Li, C. L. et al. (2006). Calculation of Water Ridge Height of Horizontal Wells in Bottom Water Reservoir. Hydrodynamics Research and Progress, 21, 374-380.

Li, H. Q., \& Meng, Y. J. (1994). Simplified Research Model of Horizontal Well Water Ridge Advancement. Journal of Northeast Petroleum University, 15, 32-35.

Liu, F. (2012). Study on the Application of Oil-Water Production Data Analysis Technology to Determine the Water Invasion Type of Horizontal Wells. China Information Society, No. 12, 67-68.

Liu, Z. Y., Cheng, B., Liu, Y. et al. (2002). Study on Horizontal Well Development: Water Ridge Change and Water Breakthrough Time Prediction of Bottom Water Reservoir. Journal of Northeast Petroleum University, 26, 100-103.

Lu, C. (2010). Study on Horizontal Bottom Hole Water Inrush. Beijing: China University of Geosciences.

Nie, B., Liu, Y. T., Yang, H. N. et al. (2012). Study on Influencing Factors of Water Coning Rise and Fall in Huan17 Block Bottom Water Reservoir. Special Oil and Gas Reservoir, 19, 84-87.

Xiao, C. Y., Li, W., Xiao, S. P. et al. (2009). Production Mechanism and Water Cut Rising Law of Edge Bottom Water Reservoir. Fault Block Oil and Gas Field, 16, 68-70.

Xin, C. P. (2011). Quantitative Description of Water Cone in Bottom Water Reservoir and Optimization of Horizontal Well Pattern Configuration. Qingdao: China University of Petroleum (East China).

Xiong, X. W., Li, Y. P., Zhang, J. L. et al. (2014). A New Method for Predicting Water Coning Performance and Water Breakthrough Time in Bottom Water Reservoir. Fault Block Oil and Gas Field, 21, 221-223. 